\title{
ethic@

OBRIGAÇÃO, AUTORIDADE E DEMANDA MORAL ${ }^{1}$

\author{
OBLIGATION, AUTHORITY, AND MORAL DEMAND
}

\author{
EVANDRO BARBOSA ${ }^{2}$ \\ (UFPel/Brasil)
}

\begin{abstract}
RESUMO
O artigo discute a relação entre obrigação e autoridade moral a partir da pressuposição endossada por Peter Strawson, R. Jay Wallace e Stephen Darwall de que moralidade se constitui como um contexto normativo relacional. Depois de destacar o problema, analiso o papel preponderante que culpa moral e atitudes reativas negativas possuem para determinar aquilo que constitui a erradez moral de uma ação. Isso posto, abordarei os tipos de obrigação moral que podemos extrair deste modelo e sua relação com o que chamarei de coeficiente de autoridade. Por fim, questiono o resultado dessa relação e apresento considerações que desafiam essa estratégia.
\end{abstract}

Palavras-chave: Autoridade; Atitudes reativas; Culpa moral; Obrigação; Normatividade.

\section{ABSTRACT}

The paper discusses the relationship between obligation and moral authority based on the assumption endorsed by Peter Strawson, J. R. Wallace and Stephen Darwall that morality exists as a relational normative context. After highlighting the problem, I discuss the ways in which moral guilt and negative reactive attitudes play a leading role in determining what constitutes the moral wrongness of an action. The last part of the paper sketches the types of moral obligation we can extract from this model and its relationship to what I will call the authority coefficient. Finally, I question the harmony of such relationship and present two considerations to challenge this strategy.

Keywords: Authority; Reactive attitudes; Moral blame; Obligation; Authority. 
(...) a moralidade é feita para o homem

e não o homem para a moralidade 3

(Frankena, Ethics, 1973).

\section{O problema}

Meu objetivo principal neste texto é apontar para a insuficiência de nos referirmos à moralidade como um domínio normativo relacional no qual o conteúdo das obrigações morais espelha o conteúdo das demandas morais correspondentes. Aqueles que defendem esta interpretação da moralidade exploram a ideia básica de que a culpa moral (moral blame) é o resultado das demandas decorrentes de atitudes reativas negativas tais como são apresentadas por Peter F. Strawson, R. Jay Wallace e Stephen Darwall. Seguirei, na primeira seção, os autores acima mencionados para defender a moralidade como um domínio normativo relacional (relational normative realm) em que os deveres e as obrigações decorrem do modo como demandas morais determinam a culpabilidade da ação. Seguirei, ainda, com a discussão iniciada por Strawson em Freedom and Resentment (1962) sobre o chamado primado da culpa moral ${ }^{4}$ e sua correlação com as atitudes reativas. $\mathrm{Na}$ seção seguinte, trato da (in)distinção entre obrigações morais e aquilo que chamarei de coeficiente de autoridade. Dentre os teóricos da tradição sobre as chamadas atitudes reativas, S. Darwall (2013) é quem discute de forma mais elaborada a relação entre obrigação e autoridade moral, por isso utilizarei seu modelo como base teórica para desenvolver o problema. Por fim, na terceira e última seção, apresentarei um contraexemplo sobre a conexão entre obrigação e culpa moral como demanda para demonstrar os limites desse tipo de interpretação sobre o que constitui o domínio moral, limites aos quais os teóricos desse modelo precisam estar atentos.

\section{Moralidade como domínio normativo relacional}

Começo oferecendo uma definição de moralidade e os seus contornos. Normalmente, adotamos diferentes normas, condutas ou comportamentos ${ }^{5}$ sobre o que consideramos ser obrigados a fazer com base em diferentes domínios normativos. Por exemplo, quando simplificamos a questão, dizemos que torturar pessoas por prazer é errado porque isso é moralmente repreensível; consideramos que 
devemos cuidar de nossos pais na velhice como um tipo de convenção social ou exigência prudencial a ser seguida; da mesma forma, admitimos que legalmente não devemos nos apropriar de bens públicos. O que esses exemplos nos mostram é que, ao explicar por que devemos agir em uma determinada direção, reconhecemos nosso compromisso com o respectivo domínio e a autoridade corresponde para demandar certas atitudes dos agentes, independentemente de tais obrigações serem do tipo moral, social, prudencial ou legal. Em outras palavras, diríamos que tais normas ou códigos criam uma esfera de comprometimento mútuo em seus domínios, indicando o que podemos exigir um do outro em termos de dever.

Deixando de lado os outros domínios e focando no da moralidade, podemos dizer que a polissemia desse termo se deve ao seu uso ordinário e pouco preciso em termos filosóficos, embora isso curiosamente não pareça diminuir seu peso na tomada de decisões cotidianas. Gert (2016) explica tais usos do termo distinguindo-o entre a dimensão descritiva e normativa, respectivamente. ${ }^{6}$ Vejamos uma possível distinção da moralidade enquanto sistema normativo.

Moralidade, como os filósofos usam atualmente o termo, refere-se a algo diferente do que quando alguém fala da moralidade da antiga Atenas ou das tribos Pashtuns do Afeganistão contemporâneo. Tampouco é o mesmo que a moralidade de qualquer indivíduo. O que nós temos em mente nesses últimos usos são costumes, hábitos sociais, normas e valores aos quais algum indivíduo se submete. Moralidades são identificadas social ou psicologicamente por meio da sua aceitação por algum indivíduo ou grupo. São, portanto, itens que podem ser estudados pelas ciências sociais empíricas, entendidas em termos amplos, talvez, para incluir princípios empáticos ou hermenêuticos. Já a moralidade como nós, os filósofos, a entendemos é um conceito essencialmente normativo e não empírico. [...] Além disso, moralidade, nesse sentido, admite apenas um uso singular. Existem muitas morais reais e possíveis (encarnadas psicologicamente e socialmente), mas há apenas uma moralidade [...] Um antropólogo, historiador ou sociólogo histórico pode nos informar sobre alguns moralidade da sociedade ou do grupo, mas a perícia desse tipo não constituiria competência sobre a questão normativa do que a moralidade exige ou mesmo no que 
a moralidade requer de pessoas que pertencem a esta sociedade ou grupo (DARWALL, 2013, p. 03). ${ }^{7}$

Estou inclinado a concordar com a ideia de Darwall de que a moralidade, a despeito de possuir uma dimensão multifacetada (sociológica, psicológica, histórica, etc.), detém uma condição normativa sui generis, uma vez que ela não "é constituída por qualquer tipo de padrão ético" (DARWALL, 2013, p. 04). ${ }^{8}$ O que importa aqui é destacar a suposição de que o domínio moral é relacional e estar moralmente ligado a outras pessoas significa que somos responsáveis por fazer parte de uma comunidade moral em termos normativos. Consequentemente, somos agentes morais autorizados não apenas a fazer exigências, mas também a recebê-las de outras pessoas dentro e a partir desse domínio. Nesse caso, fazer uma demanda moral gera um tipo de obrigação a partir da qual eu posso responsabilizá-lo e você pode fazer o mesmo quando eu não executar a ação esperada. Nesse sentido, a fonte dessa força normativa indica que fazer uma demanda moral pressupõe estar vinculado a outras pessoas, e a dinâmica desse núcleo nos torna capazes de culpar o desempenho moral de alguém.

Dana Nelkin equacional obrigação e culpa da seguinte forma:

Se $S$ é culpado por $A$, então $S$ não deveria ter feito A.

Se $S$ não deveria ter feito $A$, então $S$ poderia ter evitado fazer A (quando deve implica pode).

Portanto, se $\mathrm{S}$ é culpado por $\mathrm{A}$, $\mathrm{S}$ poderia ter evitado fazer A (NELKIN, 2011, p. 100-101). ${ }^{9}$

Há dois pontos que precisam ser esclarecidos aqui. O primeiro esclarecimento está diretamente associado à afirmação de que o deve ${ }^{10}$ (ought) se apoia na ideia de culpa como uma exigência moral. Obviamente, sua definição está no centro da discussão e muita tinta foi gasta escrevendo sobre o assunto, por isso tomarei a ideia mais ampla de culpa como equivalente a demanda para questionar o tipo de obrigação moral resultante. Dessa forma, culpa está associada ao que Strawson chama de emoções reativas negativas (negative reactive emotion) tais como ressentimento, indignação ou desaprovação. ${ }^{11}$ Nesses termos, atitudes reativas negativas são tomadas como requerimentos de moralidade (requirements of morality) ${ }^{12}$ que refletem, envolvem ou expressam demandas inescapáveis para culpar 
moralmente. Por sua vez, tais demandas são usadas como modelo ou metáfora para um requerimento permanente de moralidade (standing requirements of morality). Na visão strawsoniana, "as atitudes reativas pessoais repousam e refletem uma expectativa, uma demanda ou são a manifestação de um certo grau de boa vontade ou consideração por parte de outros seres humanos em relação a nós mesmos" (STRAWSON, 2013, p. 347). ${ }^{13} \mathrm{Em}$ suma, sua preocupação em categorizar essas atitudes repousa no fato de que a dimensão relacional da moral é interpessoal. De forma similar, Darwall - assim como Wallace (2019)14 - fala sobre o domínio moral como "uma estrutura irredutivelmente em segunda-pessoal", evidenciando que a noção de culpa como demanda é central para o deve moral, uma vez que "tais demandas devem ser capazes de serem endereçadas em segunda-pessoa" (DARWALL, 2013, p. xi). ${ }^{15}$ Novamente, a ideia por trás dessa noção de demanda é expressar que somos moralmente responsáveis um pelo outro tão somente a partir de um contexto relacional. Fora disso, a suposição moral desaparece:

Culpa e culpabilidade implicitamente direcionam demandas morais aos seus demandados e tentam reconhecer a legitimidade da demanda por seu questionado. Dessa forma, elas pretendem colocar portador e demandado em um relacionamento de reconhecimento recíproco em segunda-pessoa (DARWALL, 2013, p. 11). ${ }^{16}$

Interessa-me da discussão acima o modo como tais autores utilizam a ideia de demanda moral com um modelo ou metáfora para defender determinados requerimentos morais que se apresentarão na forma de obrigação. Ao fazer uma demanda, eu expresso a atitude reativa negativa decorrente de uma ação feita sem desculpa e moralmente culpável. Afinal, emoções negativas são uma resposta à violação de uma demanda moral ou, como afirma Macnamara, "demanda como exigência moral permanente é o tipo de material normativo com o qual as atitudes reativas negativas estão envolvidas" (2013, p. 144). ${ }^{17}$ Logo, a questão reativa das atitudes se manifesta no contexto normativo moral pela dimensão relacional pressuposta. Nesse caso, uma demanda moral carrega um fardo deôntico (deontic burden) que determina o conteúdo da obrigação correspondente à atitude reativa (MACNAMARA, 2013) ${ }^{18}$, ou seja, o conteúdo da obrigação moral 
espelha o conteúdo da demanda, a qual nada mais é do que a atitude reativa correspondente.

Como veremos, a força normativa e o caráter autoritativo que a moralidade assume é relevante porque tal caráter distintivo do universo moral vem acompanhada da pressuposição de que obrigação moral constitui uma classe especial de demandas. ${ }^{19} \mathrm{E}$ ela constitui essa classe especial porque a condição normativa exige um deve baseado na ideia de que a dimensão humana prática é relacional, ou seja, as questões morais surgem no contexto de nossa relação e não fora dela. Isso significa que reprovamos determinadas atitudes porque consideramos determinadas ações culpáveis (blameworthy). E estar moralmente conectado aos outros significa que somos moralmente responsáveis por fazer parte de uma comunidade moral enquanto um domínio normativo, ou seja, somos agentes morais autorizados a fazer exigências, mas também receber demandas dos demais.

O segundo ponto a ser esclarecido diz respeito ao tipo de responsabilidade resultante dessa visão. ${ }^{20} \mathrm{~A}$ noção de responsabilidade aqui discutida é a accountability-responsibility, de acordo com a qual fazer uma demanda moral gera um tipo de obrigação a partir da qual eu posso responsabilizar você e você pode me responsabilizar moralmente quando não realizamos a ação esperada. Nesse sentido, responsabilidade como accountability é fazer demandas que exigem um "prestar contas", diferentemente de responsabilidade como attributability. Gary Watson (2004) distingue accountabilityresponsibility e attributability-responsibility, afirmando que esta última envolve um tipo de responsabilização profunda e é feita sobre as ações que refletem os valores fundamentais do agente e capturam aquilo que Susan Wolf (WOLF, 1987) chama de "eu profundo" (Deep-Self). Por sua vez, atribuímos responsabilidade como accountability quando consideramos determinada atitude como merecedora de determinado tratamento tal como culpa ou louvor. Oshana reitera que determinadas ações são "candidatas adequadas para certos tipos de tratamento" $(1997, \text { p. } 73)^{21}$, por isso a culpa moral, que é atribuída a determinadas ações, poderia ser interpretada como o tratamento apropriado às ações erradas realizadas sem a desculpa adequada. ${ }^{22}$ Aqueles que se filiam à noção de responsabilidade como accountability a partir da dimensão relacional defenderão, assim como Darwall, que "(...) um ato é moralmente errado se e somente se seria culpável (blameworthy) se feito sem desculpa" (2013, p. 21). ${ }^{23}$ Nesse sentido, o moralmente 
obrigatório é determinado pela forma de atribuição moral da culpa como uma demanda sobre ações ou atitudes dos agentes.

Por tudo que vimos até aqui, a cadeia de argumentos nos leva às seguintes suposições:

10 suposição: a moralidade, como domínio normativo, é relacional.

$2^{\circ}$ suposição: a demanda é a expressão da atitude reativa correspondente.

$3^{\circ}$ suposição: o conteúdo da obrigação (deve) reflete o conteúdo da demanda.

Considere tais suposições a partir de um exemplo: quando Pedro coloca seu terno e gravata é porque socialmente demandamos trajes formais para uma festa de casamento e consideramos culpável, de um ponto de vista estético, sua falta de bom gosto e consideração com a regras de etiqueta. Do mesmo modo, demandamos que ele deve salvar a vida de uma pessoa sob condições apropriadas em que deve implica pode. ${ }^{24}$ Se Pedro estiver a caminho do casamento cumprindo com a demanda estética de vestir terno e gravata, consideramos que ainda assim ele deve pular ao mar e salvar uma criança do afogamento sob a condição apropriada de saber nadar. Obviamente, tal situação não oblitera a demanda por etiqueta ao molhar sua vestimenta, mas estamos dispostos a fazer um tipo de concessão ao deve estético (sem itálico) em detrimento ao deve moral como requer a $1^{\text {a }}$ suposição. É nesse sentido que a obrigação moral é entendida como uma classe especial de demandas, pois sua exigência é ex hypothesi diferente de qualquer tipo de regra prudencial, estética ou social. Se considerarmos a condição darwalliana de que uma ação errada feita sem uma desculpa apropriada merece o rótulo de culpável, então minha atitude reativa diante de inércia de Pedro ao não salvar essa criança - mesmo estando em condições adequadas para tal - tornam sua atitude culpável. Nesse caso, a atribuição de culpa é feita a partir da $2^{a}$ suposição. Como vimos, a força normativa e o caráter autoritativo que o domínio moral assume é acompanhado pelo pressuposto de que o conteúdo da obrigação moral espelha o conteúdo das demandas ( $3^{a}$ suposição) oriundos de um deve baseado na ideia anteriormente mencionada de que a prática humana é relacional.

Resta-nos, agora, explicar o tipo de autoridade necessário para fazer uma demanda moral e o tipo de obrigação decorrente dessa responsabilização pela culpa. Vou começar explicando a última. 


\section{Obrigação moral e o coeficiente de autoridade}

O objetivo desta seção é analisar os diferentes modos nos quais a obrigação moral se manifesta e aquilo que chamarei de coeficiente de autoridade moral para que os agentes possam realizar suas demandas. Utilizo a ideia de coeficiente, termo reconhecido por seu uso em álgebra, para indicar que o grau de autoridade moral que os agentes morais possuem dependerá do tipo de relação na qual eles se encontram no domínio moral. Em outras palavras, o coeficiente de autoridade de um agente é determinado por um tipo de cálculo ou consideração sobre tais condições. Apresento mais duas suposições necessárias para a discussão:

$4^{a}$ suposição: a obrigação moral acontece entre dois polos:

a. De um lado, um agente que é obrigado (o obrigado ou devedor).

b. Do outro, um indivíduo ou grupo a quem estamos obrigados, conectados ou vinculados (o obrigante ou credor).

$5^{a}$ suposição: a autoridade moral depende da localização do agente dentro do sistema moral.

Começarei com um enquadramento sobre em quais condições estamos obrigados a realizar determinada ação. Estar obrigado, no contexto prático em geral, significa que determinada ação deve ser realizada ou evitada em detrimento de outro curso de ação. Como a estrutura da minha discussão toma o projeto filosófico inaugurado por P. F. Strawson como um guia para discutir a relação entre obrigação e culpa moral, discutirei o problema da obrigação como estando diretamente relacionada ao que eu e você fazemos para merecer elogio ou culpa com bases nessa condição relacional da moralidade. Strawson (2013, p. 343-46) chama de "context of ordinary interpersonal relationships", Wallace (2019) chama de "relational interpretation of moral nexus" e Darwall (2013, p. xiii), de forma mais incisiva, chama de "relational duty". Começo esclarecendo em que medida obrigações morais podem ser distinguidas de acordo com o tipo de relação entre os agentes.

Uma maneira de observar isso é através da distinção que Frankena (1975) ${ }^{25}$ estabelece entre julgamentos de obrigações morais particulares e julgamentos de obrigação em geral. Uma obrigação moral geral afirma que "devemos respeitar as promessas feitas" e vale em sua forma mais ampla. Nesse caso, é uma obrigação manter a 
promessa e seria errado não cumpri-la, independentemente do contexto relacional em que ela se manifesta. Por outro lado, uma obrigação moral particular se manifesta em um caso específico quando, por exemplo, "John promete devolver o livro que pegou emprestado comigo no início da próxima semana":

Darwall (2013, p. xiii) possui uma definição mais elaborada dessa distinção entre o que chama obrigação como tal e obrigação bipolar:

Ao contrário da ideia de obrigação moral como tal, as obrigaç̃oses bipolares não são apenas de devedores (obligors), agentes que estão sujeitos à obrigação, mas também de obrigantes (obligees), aqueles a quem a obrigação é devida. Elas implicam, portanto, uma reclamação correlativa de que o obrigante deve reclamar do devedor o comportamento que o devedor é obrigado a realizar em relação ao obrigante. (...) Ambos os conceitos são mostrados como em segunda-pessoa, porém de modos distintos. Alguém está moralmente obrigado como tal a fazer algo apenas no caso em que seu ato é algo que qualquer um (incluindo ele mesmo) justificadamente requer dele na condição de pessoa representativa. E alguém é obrigado em relação a outro a fazer algo apenas no caso de o credor ter a autoridade discricionária individual para fazer exigências do devedor como obrigado e responsabilizar pessoalmente 0 devedor. ${ }^{26}$

Há alguns pontos que precisar ser esclarecidos aqui. Considere que Thaís fez a promessa a Kety de que iria assistir ao jogo do time de seu amigo caso ele chegasse na final do campeonato estadual. Embora Thaís, a devedora (the obligor), não torça para o mesmo time que sua amiga, ainda assim ela se considera em um contexto relacional de um deve que a obriga a realizar a ação sob o risco de violar a promessa e prejudicar Kety, a obrigante (the obligee). Isso indica um tipo de obrigação bipolar segundo a qual Kety "(...) possui uma posição ou autoridade normativa distinta em relação àquele que promete [Thaís] que terceiros não possuem" (DARWALL, 2013, p. 20). ${ }^{27}$ Kety, dada a situação de ver a promessa quebrada, poderia culpar Thaís por isso com uma queixa do tipo "Mas eu estava contando com você!"28 para expressar seu ressentimento ou indignação. 
Se nos colocarmos no lugar de Kety, então podemos perceber o que se segue:

Obrigações bipolares exigem a relação entre devedor $e$ credor moral, ou seja, elas pressupõem a relação entre os agentes (devedor e credor) para que a promessa tenha "peso" de obrigação. Em outras palavras, "[...] para que uma obrigação bipolar exista alguma ação deve prejudicar um promissor; deve constituir um erro e não apenas um ponto equivocado. [Por outro lado] [...] a existência de um credor faz parte do conceito de uma obrigação bipolar, embora não seja para obrigação moral como tal (DARWALL, 2013, p. 21).

Uma maneira de observar como o domínio normativo e os tipos de obrigação nele presentes pode ser observado pelo que Michael Thompson (2004) chama de ordem deontológica (deontological order), definida por categorias deontológicas monádicas, e ordem dikaiológica (dikaiologic order):

(1) Fazer A é errado (inadmissível).

(2) Não fazer A é moralmente obrigatório.

(3) Fazer B é moralmente admissível (não errado).

(4) Não fazer B não é moralmente obrigatório.

[A ordem dikaiológica faz um complemento:]

(5) $X$ prejudicou $Y$ fazendo $A$.

(6) $X$ tem um dever para $Y$ não fazer $A$.

(7) $Y$ tem um direito para $X$ que $X$ não faça $A$. (DARWALL, 2013, p. 27) 29

Transcrevo a posição de Darwall nos seguintes termos:

1. Deontological order - Condição de dever relacional per si.

Obrigação como tal: X é moralmente obrigado a realizar A.

2. Dikaiological order - Condição de dever relacional entre credor e devedor.

Obrigação bipolar: X é moral obrigado a realizar A para Y. 
Do ponto de vista deontológico, Thaís é obrigada a ir ao jogo ou seja, performar A - porque existe um julgamento moral que a torna responsável em termos de obrigação como tal, (1) - (4). Por causa de sua condição geral, a comunidade moral exige que "devemos cumprir nossas promessas", que poderiam ser aplicadas não apenas à relação entre Kety e Thaís, mas também a outros indivíduos em situações semelhantes. Por outro lado, a obrigação bipolar insere a condição dikaiológica (5), (6) e (7) para a realização da ação. Isso significa que Thaís está moralmente obrigada a fazer A também por causa de sua relação bipolar com Manoel $(Y)$. Nesse caso, a obrigação é do tipo bipolar exatamente porque há um promissor e um proeminente, enquanto a obrigação como tal descarta essa condição relacional de dois polos. Sob tais condições, assumir a moralidade como um sistema normativo significa assumir que somos parte de uma comunidade moral. Todos estão em uma condição relacional e ambas são demandas legítimas do ponto de vista moral, mas de modo algum idênticos. Isso explica a $4^{a}$ suposição.

Seguindo adiante para a $5^{a}$ suposição, eu gostaria de analisar o problema da autoridade legítima para demandar moralmente. Como eu disse, a configuração do sistema de obrigações morais envolve, ainda, uma análise sobre o tipo de autoridade requerida para que alguém faça uma demanda e, consequentemente, obrigue alguém a realizar (ou evitar) determinada ação. Chamarei isso de determinação do coeficiente de autoridade, visto que qualquer teoria moral baseada nessa dimensão relacional do dever pressupõe como relevante o ponto de vista que o(s) agente(s) assumem no cenário moral em questão. Wallace (2014) não utiliza o termo "demanda" e fala em "expectativas" para tratar a questão, mas ele parte do mesmo pressuposto de que nossas demandas são flexíveis e se manifestam a partir de nossa posição no jogo moral. Ele chama isso de condição de autonomia (condition of autonomy), a qual é necessária ao agente para que possamos responsabilizá-lo do ponto de vista moral. Segundo ele, esperamos que um artista experiente realize um trabalho mais elaborado, por exemplo, do que uma criança que se diverte pintando um quadro em branco com os dedos sujos de tinta. Para ele, nossa expectativa sobre o desenho do artista profissional é muito maior. Isso reflete o quanto o contexto relacional ajuda a determinar o tipo de expectativa que temos uns sobre os outros (Cf. WALLACE, 1994, p. 5253). ${ }^{30}$ Similarmente, é nesse sentido que devemos considerar em que medida as obrigações morais são demandas morais genuínas e 
perguntar sobre quem tem autoridade para exigi-las. Consequentemente, o aspecto normativo distinto do conceito de obrigação bipolar e obrigação moral como tal indicam que tais obrigações envolvem autoridades distintas. Enquanto obrigação bipolar pressupõe autoridade individual do obrigante, obrigação como tal pressupõe uma autoridade representativa que "qualquer pessoa, na condição de membro representativo da comunidade moral, possui para responsabilizar a si mesmo e aos outros pelo cumprimento através de atitudes reativas impessoais" (DARWALL, 2013, p. 32). ${ }^{31}$ O exemplo de Strawson (2013) ${ }^{32}$ de alguém que possui a atitude reativa negativa de ressentimento (resentment) quando alguém pisa acidentalmente sobre minha mão tentando me ajudar é ilustrativo aqui. Nesse caso, o indivíduo que pisa na minha mão está diretamente relacionado a mim em um "nexo prático" que me permite fazer uma demanda direta ${ }^{33}$. Se considerar sua atitude proposital, posso assumir uma posição privilegiada de autoridade individual e responsabilizá-lo diretamente por meio de uma atitude reativa negativa tal como o ressentimento. $A$ demanda que faço irá espelhar o conteúdo da minha atitude reativa e me autorizar a culpar tal ação. Agora, se eu sinto que não houve intenção de me ferir, e uma ação é errada apenas quando feita sem desculpa apropriada, então não posso sequer oferecer o perdão a ele, pois, como vimos, uma desculpa adequada bloqueia a inferência entre ação errada e culpabilidade. ${ }^{34}$

Por sua vez, a autoridade representativa está associada à obrigação moral como tal e envolveria um tipo de atitude reativa impessoal como desaprovação. Considerando o exemplo acima, Kety ficará ressentida se Thaís cumprir sua promessa, enquanto nós desaprovaríamos sua ação à distância, ou seja, a partir do ponto de vista da comunidade moral. Da forma como compreendo essa questão, o aspecto normativo distintivo da moralidade pressupõe essa dimensão relacional para pautar as condições sob as quais posso atribuir culpa e responsabilizar alguém por realizar determinada ação. Logo, a atribuição de responsabilidade repousa sobre o coeficiente de autoridade correspondente. Por um lado, o grau de autoridade que possuo como membro da comunidade moral diz respeito à autoridade que todos possuímos para fazer certas exigências. Por outro, existe um grau de autoridade individual que transcende minha condição de membro de uma comunidade moral. Aqui, eu posso fazer demandas diretas entre obrigante e obrigado. 
Não obstante, essa compartimentalização da obrigação em diferentes graus de autoridade parece não abarcar o fenômeno moral em sua totalidade, pois, mesmo se assumirmos que existe um ponto de vista de segunda pessoa como ponto de partida para o reino moralnormativo, isso não implica que devemos admitir seus desdobramentos. O que farei, aqui, é questionar o seu alcance. Particularmente, defenderei que há certos casos em que os dois tipos de autoridade entram em conflito basicamente porque os binômios obrigação bipolar - autoridade individual e obrigação como tal autoridade representativa não operam sempre de forma harmoniosa. E como ambos são derivados do ponto de vista da segunda pessoa, não podemos identificar quem tem autoridade decisiva com base na estratégia do ponto de vista da segunda pessoa. Essa seria uma circularidade que gostaríamos de evitar. Ademais, não conseguimos determinar um coeficiente de autoridade que nos diga se é o indivíduo ou a comunidade que estão corretos e por que estão corretos. Essa seria uma falha interna ao próprio sistema moral de Darwall. Vejamos.

\section{O conflito entre autoridades: um contraexemplo}

Como vimos, obrigações morais estão conceitualmente ligadas aos conceitos de autoridade e demanda moral sobre uma base comum: a ideia strawsoniana de uma dimensão interpressoal, a noção de nexo moral de Wallace e o chamado ponto de vista da segunda-pessoa de Darwall. Sigo a fenomenologia da moralidade assumida por esses autores $^{35}$ para afirmar que nos colocamos como moralmente responsáveis por meio da atitude distintamente moral da culpa, através da qual tratamos as demandas como sendo supostamente legítimas. Nesse sentido, aquilo que é "moralmente obrigatório é o que a moralidade demanda" (DARWALL, 2013, p. 33). ${ }^{36}$

Isso posto, podemos dizer então que a força normativa da obrigação moral decorre do tipo de demanda moral implícita na ação. Por isso, a culpa, como fenômeno moral, indica que devemos atender a certas demandas que não se originam de uma autoridade individual, mas da condição de ser, antes de tudo, membro representativo da comunidade moral. Isso ocorre porque as atitudes reativas que originam nossa demanda por culpa moral pressupõem o deve relacional da comunidade moral. Nesse caso, culpa moral pressupõe autoridade representativa como complementar à autoridade individual (Darwall, 2013). ${ }^{37}$ Minha desaprovação da atitude de Thaís por quebrar sua 
promessa de ir ao jogo com Kety tem sua origem em assumir (a) que eu tenho razões em terceira pessoa para demandar que ela cumpra sua promessa. No entanto, essa autoridade que suponho não provém da minha condição individual, mas de (b) uma condição de autoridade representativa como membro da comunidade moral. Se alguém possui autoridade individual (c), certamente é Kety, que está em uma condição privilegiada para culpar a atitude errada da amiga - tão logo ela não esteja acompanhada da desculpa adequada de um ponto de vista moral. O mesmo não acontece quando considero aquele que pisa na minha mão propositadamente como merecedor de culpa e sua ação perversa. Aqui, eu sou o obrigante e ele o obrigado; já no exemplo de Thaís e Kety, eu sou um membro da comunidade moral.

A atribuição de culpa, que se expressa por uma violação da obrigação moral como tal, depende da existência de uma autoridade para demandar que qualquer membro da comunidade moral possui. Sempre que culpamos alguém, estamos assumindo que este é um requisito feito por todos os membros da comunidade moral $a b$ initio. Por conseguinte, a atribuição de culpa em uma relação moral direta exige que o credor (neste caso, Kety para com Thaís, e eu para com quem pisa na minha mão) possua uma "base privilegiada de reclamação" em relação ao demandado que qualquer outro membro da comunidade moral não dispõe (DARWALL, 2013). Do ponto de vista da comunidade moral, "se $X$ tem uma obrigação para $Y$ de fazer $A$ e, portanto, $Y$ possui uma reivindicação contra $X$ que $X$ faça $A$, a falha de $X$ em fazer $A$ não é apenas errada para $Y$, ela seria errada, mantendose o resto igual, também como tal" (DARWALL, 2013, p. 38-39). ${ }^{38}$

Com isso, podemos tecer algumas conclusões sobre as posições que ocupamos no jogo moral:

(a) Minha desaprovação a Thaís surge de uma autoridade representativa vinda da comunidade moral, enquanto minha reprovação àquele que pisa em minha mão surge de minha autoridade individual para demandar.

(b) As razões que ofereço para o caso de Thaís e Kety representam um tipo de obrigação como tal, enquanto eu tenho obrigação bipolar para com aquele que pisa em minha mão.

(c) Somente Kety pode fazer exigências ou demandas legítimas a partir de uma autoridade 
individual para com Thaís, tendo em vista que a última é a obrigada e a primeira é a obrigante nessa relação bipolar. Da mesma forma, apenas eu possuo autoridade para demandar culpa moral direta sobre quem machuca minha mão pisando nela.

Ao que parece, temos dois caminhos a seguir. Podemos ter um tipo de convergência moral muito afinada, em que atitudes reativas em uma condição bipolar ou como membro da comunidade moral ocorrem de uma única maneira. Se esse for o caso, aquilo que Wallace chama de condição de autonomia para que sejamos responsáveis parece estar comprometida, ${ }^{39}$ pois um agente autônomo não poderia ser subordinado à ideia de responsabilidade coletiva sem colapsar essa condição. Ou, por outro lado, concordamos que a característica relacional do contexto moral normativo define o tipo de autoridade. Nesse caso, a autoridade representativa e a individual podem ser dissonantes.

Vejamos um contraexemplo ao que foi oferecido até então para desafiar o coeficiente de autoridade que cada relação pressupõe, considerando apenas os elementos morais dele. Walter é um advogado bem-sucedido que resolveu deixar a presidência de sua companhia depois de longos anos à frente dos negócios. Ao longo de sua vida, os traços de caráter de Walter foram moldados a partir de sua regra de ouro: jamais tolerar qualquer tipo de privilégio. Para escolher 0 sucessor de sua empresa, ele decide fazer uma entrevista com os postulantes ao cargo. Para isso, todos os candidatos deveriam chegar às 8:00 em ponto do dia marcado e eles seriam entrevistados seguindo o critério de ordem alfabética. Dentre um número excepcional de bons candidatos concorrendo à vaga encontram-se seu filho, Gustavo. Ele, que é seu filho preferido, é também o mais problemático em termos de comportamento por deter traços de caráter questionáveis como seguir à risca a "Lei de Gérson" de sempre obter vantagem não importam as questões morais envolvidas. Por outro lado, seu pai, Walter, jamais tolerou qualquer tipo de privilégio. No dia da entrevista, Gustavo chega atrasado e ainda faz uma requisição: ele exige ser o primeiro a ser entrevistado.

De que forma Walter, os candidatos e a comunidade moral deveriam reagir frente a esse comportamento? Conforme vimos, um ato pode ser moralmente culpável e considerado errado quando feito sem desculpa. Mais do que isso, essa culpa não repousa sobre a ação, 
visto que "obrigação e erradez são normativos não para a ação, mas para as atitudes reativas strawsonianas" (DARWALL, 2013, xiv). ${ }^{40}$ Isso é o que sugere a conexão entre ter uma atitude reativa e fazer demandas como uma metáfora para dizer que, do ponto de vista moral e normativo, podemos culpar determinadas ações. Se assim for, atitudes reativas negativas são expressas como demandas e o conteúdo de obrigação espelham tal conteúdo. Dessa forma, posso culpar moralmente uma ação feita sem uma desculpa adequada, pois o deve do domínio moral se expressa normativamente na obrigação correspondente. Como vimos, o ponto de partida para esse tipo de visão sobre o moralmente obrigatório é a pressuposição strawsoniana básica de que todos estamos envolvidos naquilo que chama de relações interpessoais ordinárias (ordinary interpersonal relationships). E estando em um contexto relacional como o universo moral normativo, tais atitudes reativas gerariam demandas morais que faríamos uns sobre os outros em níveis distintos. Logo, culpar alguém é lançar mão dessa autoridade para demandar.

Entretanto, para que isso ocorra, algum nível mínimo de autoridade legítima é necessário. O problema surge quando tomamos a dimensão da responsabilidade moral (accountability) como relacional e sendo expressa em segunda-pessoa, dividindo a obrigação em classes, bipolar e como tal, imaginando que ambas estão em uma relação simétrica e harmoniosa simplesmente porque ambas derivariam de um deve do domínio moral. Minha sugestão é que essa conclusão não procede exatamente porque as demandas resultantes das atitudes reativas dos indivíduos são distinguidas pela especificidade de cada relação e de nossa posição quando o jogo moral está sendo jogado. A dinâmica relacional fornece a cada agente uma posição única de autoridade, embora todos estejamos sob a égide do domínio moral. No caso acima exposto, a autoridade representativa que possuo como membro da comunidade moral me permite culpar tanto Walter quanto Gustavo pela erradez de sua ação: o primeiro por permitir que seu filho faça a entrevista e o segundo por chegar atrasado. Isso porque podemos imaginar que a demanda que eu faço é a expressão de minha atitude reativa negativa de indignação se ele for aceito na entrevista e passar à frente dos demais. Por sua vez, Walter possui autoridade individual e está em uma relação direta de obrigante e obrigado com Gustavo, e pode ir na mesma direção não o autorizando a fazer a entrevista. Nesse caso, a culpa assumiria a forma de uma sanção. Todavia, não há garantias de que Walter seguirá por 
esse caminho. Se em sua relação com o problemático filho ele já considera uma vitória o fato de Gustavo ter aparecido para a entrevista, ou seja, ele superou sua expectativa, o resultado não será uma demanda de culpa, mas um elogio. Logo, se a avaliação da ação decorre da atitude reativa equivalente, podemos dizer que ambos (comunidade moral e Walter) estão corretos em demandar culpa e elogio a partir de seus respectivos espaços de autoridade. Isso seria o equivalente a dizer que a ação mereceria, simultaneamente, culpa e louvor. Se considerarmos, ainda, os demais candidatos da entrevista, não fica claro em qual tipo de posição relacional eles se encontram para demandar. Eles parecem estar muito próximos para serem consideramos meros expectadores da comunidade moral; por outro lado, eles não estão diretamente postados em um dos polos da relação bipolar. Isso compete a Walter e Gustavo. Se a dinâmica da fenomenologia moral nos ensina alguma coisa é que podemos imaginar outras situações que comprometem o equilíbrio entre os tipos de autoridade.

Macnamara, por exemplo, questiona a delicada relação autoridade legítima para fazer demandas e atitude reativa correspondente. Para ela, em muitas situações, podemos ter atitudes reativas negativas para fazer determinadas demandas aos outros, entretanto não possuiríamos autoridade para tal. Em seu exemplo, Macnamara (2013) apresenta a seguinte situação: você está em um trem lotado quando entra um casal de idosos que deseja permanecer sentados juntos, mas não há mais espaço de dois lugares. Eles, então, se dirigem a um jovem sentado e perguntam se ele poderia trocar de lugar para que ambos pudessem se sentar um ao lado do outro. Porém, o jovem se recusa a trocar de lugar baseado na premissa sobre como funciona a dinâmica da escolha de assentos no trem: "quem chega antes, escolhe primeiro!" Macnamara indica que, apesar da justificativa do jovem, ainda assim nós poderíamos ter uma emoção reativa negativa de reprovação sobre sua atitude, mesmo que não tenhamos autoridade para demandar dele que troque de lugar com o casal de idosos. Nesse caso, temos uma atitude reativa negativa para atribuir culpa à ação do jovem, mas não possuímos autoridade para fazer tal demanda. $E$, em alguns casos, essa atitude não é sequer seguida pela autoridade equivalente.

Eu organizei minha discussão seguindo esta ordem de suposições: 
$1^{\text {a }}$ Suposição: A moralidade, como domínio normativo, é relacional.

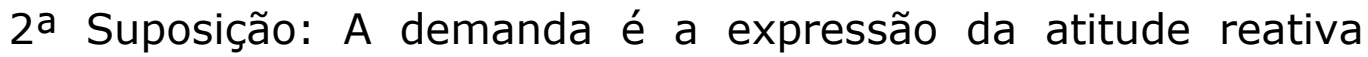
correspondente.

$3^{a}$ Suposição: O conteúdo da obrigação (deve) reflete o conteúdo da demanda.

4a Suposição: O tipo de obrigação moral depende da dinâmica relacional.

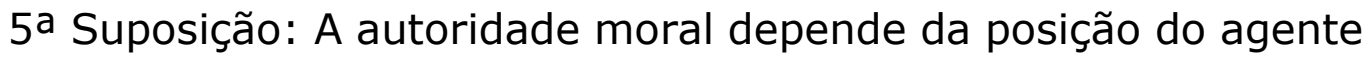
dentro do sistema moral.

Aparentemente, a $1^{\text {a }}$ suposição é um fardo pesado demais para a teoria de Darwall carregar. Por outro lado, ela parece acomodar a $2^{a}$ e a $3^{a}$ suposições muito bem com sua dinâmica reativa para determinar a demanda moral correspondente. Como vimos, o conteúdo da obrigação moral realmente parece refletir o conteúdo da demanda, tornando-a uma classe especial de obrigação. Além disso, a $4^{a}$ suposição explica como a natureza das obrigações morais é dividida. Obviamente, as observações apresentadas acima não falsificam a estratégia relacional, principalmente na teoria de Darwall. Como eu disse, meu principal objetivo era demonstrar o desafio desse modelo para acomodar adequadamente a autoridade e a obrigação moral. Não obstante, podemos extrair consequências desencorajadoras para aqueles que se filiam a este modelo. Se considerarmos a atribuição de culpa moral como um tipo de demanda baseada nas diferentes atitudes reativas que possuímos, então culpa moral possui uma natureza posicional (positional nature of blame). ${ }^{41} \mathrm{E}$ se sua natureza posicional implica que a autoridade moral pressupõe a moralidade como um domínio relacional, então podemos considerar que Walter seria autorizado a encarar a atitude de seu filho Gustavo com bons olhos, ou seja, aprová-la. Por sua vez, os demais candidatos também julgariam moralmente sua atitude; entretanto, considerando a natureza posicional de seu julgamento, eles poderiam culpar e não louvar a atitude de Gustavo. E você e eu, como membros da comunidade moral, também estaríamos inclinados a condenar a ação. Por fim, se nós consideramos que julgamentos sobre ações erradas são julgamentos que dizem respeito tão somente à noção de culpa como resultado de sentimento moral adequado, podemos dizer que a própria noção de expectativa (expectation) foi corrompida apenas em parte no exemplo de Walter e Gustavo. Nesse caso, o binômio autoridade individual e obrigação bipolar não é acompanhado pelo julgamento moral adequado 
ou é inconsistente com o binômio autoridade representativa e obrigação como tal. Sendo assim, entre autoridades não seríamos capazes de determinar um coeficiente de autoridade que nos diga se 0 indivíduo ou a comunidade está correto e por que está correto. 


\section{Notas:}

${ }^{1} \mathrm{O}$ trabalho aqui apresentado é o resultado de parte da pesquisa realizada na University of North Carolina - Chapel Hill durante meu estágio pósdoutoral. Agradeço à Coordenação de Aperfeiçoamento Pessoal de Nível Superior-Capes pela bolsa de estudos concedida, modalidade Professor Visitante Júnior 2019-2020. Uma versão preliminar com os conceitos centrais da teoria de Darwall foi apresentada em Barbosa (2018a), contudo a tese aqui apresentada é inédita. Sou grato pelos comentários feitos pelos colegas durante minha apresentação no GT de Ética no XVIII Encontro Nacional da ANPOF e ao professor Stephen Darwall pelos encontros na Yale no inverno de 2019 para discutir o problema aqui apresentado e esclarecer vários pontos de sua teoria. Ideias dissonantes e equívocos quanto ao que ele apresenta em sua proposta original são de minha responsabilidade. Agradeço ao Professor Geoffrey Sayre-McCord (UNC-Chapel Hill) pela orientação em minha pesquisa pós-doutoral e por discutir pontos fulcrais do presente artigo em uma versão em língua inglesa. Agradeço aos colegas do grupo de estudos que discutiram a versão final do texto: Thaís A. Costa, Celina Brod, Gustavo Generaldo, Guilherme Meneghello, Emerson F. de Almeida e Bruna Schneid.

2 Professor dos Programas de Graduação e Pós-Graduação em Filosofia da Universidade Federal de Pelotas - UFPel. E-mail: evandrobarbosa2001@yahoo.com.br; Orcid-iD: https://orcid.org/0000$\underline{0002-5695-3746}$

${ }^{3}$ Tradução minha. No original: "(...) morality is made for man, not man for morality".

${ }^{4}$ Naquilo que Audrey L. Anton (2015) chama the primacy assumption, quando nossas avaliações morais sobre uma ação ser ou não merecedora de culpa (blame) ou elogio (praise), o primado teórico da culpa detém lugar de destaque nas discussões filosóficas sobre o tema. Nesse caso, a teoria strawsoniana foi (e talvez ainda seja) a teoria mais influente sobre o modo como interpretamos o problema. (COATES \& TOGNAZZINI, 2013, item 1.2).

5 Há uma vasta gama de termos que são cotidianamente utilizados para expressar nossas demandas morais no intuito de vê-las cumpridas. D. Baker apresenta um pouco dessa variedade: "There are things we should do, and other things we should not. Some choices are permitted, others are required, and others are impermissible. Some behavior is appropriate, some feelings unwarranted. Happiness is good. Nazis are bad. Italian fascists are also bad, but Nazis are worse. Some think eating meat is immoral; others, that mentioning such beliefs in the presence of the Thanksgiving turkey is impolite. Double-parking is illegal; so is murder, even murder of a Nazi. We use these terms, in some sense, to tell people what to do, what to think, and how to feel-that is, we use them to prescribe, forbid, and advise. We also use them to praise, censure, and evaluate. Finally, we use them to justify. If I did what I was supposed to, any criticism others might register is off base" (2017, p. 567). 
6 Eis a distinção: "1. Descriptively to refer to certain codes of conduct put forward by a society or a group (such as a religion), or accepted by an individual for her own behavior, or 2 . Normatively to refer to a code of conduct that, given specified conditions, would be put forward by all rational persons." (https://plato.stanford.edu/entries/morality-definition. Acessado em 20 de Junho de 2020). Veja também sua obra The Definition of Morality (2005), mais especificamente "Part I - Conceptual Foundations".

7 Tradução minha. No original: "Morality, as philosophers currently use the term, refers to something different than it does when someone speaks of the morality of ancient Athens or that of Pashtun tribes of contemporary Afghanistan. Neither is it the same as any individual's morality. What we have in mind in these latter uses are social mores or customs, or norms and values to which some individual subscribes. Moralities are identified socially or psychologically, via their acceptance by some individual or group (...) Morality, as we philosophers now understand it, however, is an essentially normative rather than an empirical concept, however broadly "empirical" might be understood. Moreover, "morality" in this sense admits of only a singular use. There are many actual and possible moralities (embodied psychologically and socially), but there is only one morality. An anthropologist, historian, or historical sociologist might inform us about some society's or group's morality, but expertise of these kinds would not constitute competence on the normative question of what morality requires, even on what morality requires of people who belong to that society or group. Facts about the mores actually in place would of course be relevant to the latter question, but they would not settle it."

8 Tradução minha. No original: "[morality] is not constituted by just any ethical standards either". Sobre esse ponto, Darwall segue a caracterização de Gertrude E. M. Anscombe e de Henry Sidgwick em relação à "filosofia moral moderna" para afirmar que o pensamento ético moderno é essencialmente concebido com as noções quase-legais de obrigação, dever e lei. Em seu artigo seminal Modern Moral Philosophy (1958), Elizabeth Anscombe argumenta contra os limites da visão moderna de moralidade afirmando que os conceitos de obrigação e dever moral não são encontrados entre os antigos. Em suas críticas, ela argumenta que muitos teóricos da moral, inclinados a concordar com tal visão, discutem o problema da moralidade de maneira negligente como, nas suas palavras, "(..) alguém cujas mandíbulas de alguma forma ficaram desalinhadas: os dentes não se encaixam em uma mordida apropriada" (1998, p.97). Darwall resgatará a análise de Anscombe sobre o viés jurídico oferecido pela filosofia moderna à moralidade por dizer que a visão moderna não faz uma distinção adequada entre moral e lei, concordando com a ideia - que também será apoiada por P. Strawson - de que estamos sob a égide da moralidade não por causa de acordos legais e/ou convenções, mas simplesmente porque compartilhamos uma condição comum de agentes morais. Do mesmo modo que Anscombe, Sidgwick apresenta contraste semelhante em The Methods of Ethics (1874) ao afirmar que, na filosofia grega em geral, havia uma faculdade de regulamentação reconhecida como Lógos ( $\lambda$ óyos). Na modernidade, esse 
conceito é cindido e encontramos um dualismo entre razão universal e razão egoísta ou amor próprio (self-love) que evidencia o antagonismo de interesses presente nas considerações dos indivíduos. Sidgwick, como tantos outros, concorda que a filosofia moderna estabeleceu um novo domínio para a moralidade, distanciando-se da tradição antiga ao centrar suas discussões sobre o deve (ought) em detrimento ao bom (good). No Prólogo de The Sources of Normativity (1996), C. Korsgaard afirma que o centro da Ética foi deslocado na passagem do mundo antigo para o mundo moderno. Para os gregos, Ética era o reino do valor e a noção de excelência possuía força atrativa, ou seja, nos movíamos em direção (télos). Por sua vez, modernos reposionam o problema e a ideia de obrigação surge como naturalmente associada à ideia de lei. Nesse caso, sua força era compulsiva. Nas suas palavras: "When we seek excellence, the force that value exerts upon us is attractive; when we are obligated, it is compulsive. For obligation is the imposition of value on a reluctant, recalcitrant, resistant matter. Obligation is the compulsive power of form" (p. 4).

9 Tradução minha. No original:

"If $S$ is blameworthy for $A$, then $S$ ought not to have done $A$.

If $S$ ought not to have done $A$, then $S$ could have refrained from doing $A$ (from Ought implies Can)

So, if $S$ is blameworthy for $A$, then $S$ could have refrained from doing A."

Pereboom (2013) analisa a relação entre obrigação e culpa sem as chamadas atitudes reativas "clássicas" (indignação e ressentimento), mas atitudes alternativas como raiva moral (moral anger) e tristeza (sadness). Em alguns casos, conclui ele, é preferível dissociar culpa de atitudes reativas.

10 Utilizarei o termo deve em itálico ao longo do texto para me referir à tradução do termo inglês ought e para distingui-lo de seu uso não moral. Ainda assim, é importante mencionar que deve é polissêmico mesmo entre os filósofos. Nesse caso, uma forma de entendê-lo pode ser distinguindo-o, seguindo Girlbert Harman (1977), entre o deve que se aplica à ação e o deve que se aplica ao estado de coisas: "ought to do implies that an agent has a reason to perform an action, whereas an ought to be evaluates a state of affairs and does not by itself imply that any particular agent has a reason to contribute to bringing about the state of affairs" (p. 87).

11 Nesse sentido, o caráter relacional do aspecto normativo do reino moral indica que fazer uma demanda moral está diretamente associada ao conceito de culpa moral, embora sua definição seja palco de discussão. Por exemplo, Georg Sher, em In Praise of Blame (2006) se afasta dessa visão ao afirmar que culpa decorre da relação entre a crença (belief) de que determinada ação realizada é errada e o desejo (desire) de culpar aquele que realiza a ação errada. Para uma interlocução mais recente sobre o problema da culpa moral, compare a análise de T. M. Scanlon em Moral Dimensions: Permissibility, Meaning, Blame (2008), especialmente o capítulo 04, e a resposta crítica de S. Wolf em Blame, Italian Style, 2011. 
12 Strawson, Watson e Wallace utilizam os termos demanda moral, obrigação moral, requerimento moral e expectativa moral de forma intercambiáveis (MACNAMARA, 2013).

13 Tradução minha. No original: "personal reactive attitudes rest on, and reflect, an expectation of, and demand for, the manifestation of a certain degree of goodwill or regard on the part of other human beings towards ourselves."

${ }^{14}$ Em seu trabalho mais recente The Moral Nexus (2019), cujo título fala por si, Wallace afirma que "it may be thought of as a normative nexus that link us individually with each of the persons who might potentially be affected by what we do" (Wallace, 2019, p. 01). É esse tipo de relação que está em jogo aqui.

15 Tradução minha. No original: "(...) "demands that must be capable of being addressed second personally."

16 Tradução minha: No original: "Blame and guilt implicitly address moral demands to their objects and bid for their object's recognition of the demand's legitimacy. In this way, they purport to place bearer and object into a relationship of reciprocal second- personal recognition."

17 Tradução minha. No original: "demand qua standing moral requirement are the kind of normative material with which negative reactive attitudes are concerned".

18 Segundo Macnamara (2013), uma das consequências imediatas de interpretar o domínio moral dessa forma é que este ficaria cindido entre reino deôntico (deontic realm) e reino avaliativo (evaluative realm). Isso geraria uma redução do espaço moral, pois estaria em jogo tão somente a análise sobre a erradez da ação e não a avaliação da ação em termos de bom ou mau.

19 Pego emprestado essa definição de obrigação moral como uma classe especial de demanda (special class of demand) de R. Jay Wallace (1994, p. 128).

20 Novamente, há uma vasta literatura sobre o tema da responsabilidade moral relacionando-o a diferentes questões que estão, direta ou indiretamente, relacionadas a minha discussão nesse artigo. Para a relação entre liberdade e responsabilidade moral, confira Harry Frankfurt "Alternative Possibilities and Moral Responsibility" (1969); "Freedom of the Will and the Concept of a Person" (1971); Thomas Nagel, "Moral Luck" na obra Mortal Questions (1979); Susan Wolf "Sanity and the Metaphysics of Responsibility" (1988) . Sobre os diferentes tipos de responsabilidade, confira também Marina Oshana, "Ascriptions of Responsibility" (1997); Gary Watson, "Two Faces of Responsibility" (1996); David Shoemaker, "Attributability, Answerability, and Accountability: Toward a Wider Theory of Moral Responsibility" (2011); Cheshire Calhoun, "Responsibility and Reproach" 
(1989). Sobre a relação entre responsabilidade, culpa e atitudes reativas, veja T.M. Scanlon, Moral Dimensions (2008); Marilyn Frye, "A Note on Anger" (1983); Susan Wolf, "Blame, Italian Style" (2010); Jay Wallace, "Dispassionate Opprobrium: on Blame and the Reactive Sentiments" (2011) e Macalester Bell, "A Woman's Scorn: Toward a Feminist Defense of Contempt as a Moral Emotion" (2005).

21 Tradução minha. No original: "suitable candidate for certain kind of treatment."

22 Outra forma de julgamento moral é o elogio atribuído à atitude ou ação do agente. Este é um tema que, em geral, tende a passar ao largo das discussões sobre responsabilidade. Esta assimetria se explica, segundo Watson, porque as atitudes erradas e a consequente culpabilidade envolvem aspectos mais determinantes de nossas vidas: "We seem to have a richer vocabulary of blame than of praise. This slant is not due solely to mean-spiritedness. At least part of the explanation is that blaming tends to be a much more serious affair; reputation, liberty, and even life can be at stake, and understandably we are more concerned with the conditions of adverse treatment than with those of favorable treatment" (2004, p. 283). Nesse sentido, não atribuir culpa e consequente sanção ao assassino parece ter consequências mais sérias do que deixar de elogiar o bom atleta por sua performance $\mathrm{e}$ profissionalismo.

${ }^{23}$ Tradução minha. No original: "an action is wrong if, and only if, it would be blameworthy to perform the action without adequate excuse". Sobre a relação sobre o significa de desculpa moral, confira Gideon Rosen "Skepticism about Moral Responsibility" (2004); Michele Moody-Adams "Culture, Responsibility, and Affected Ignorance" (1994); Robert Adams "Involuntary Sins" (1985). Há uma distinção importante a ser feita sobre as condições que inibem a responsabilidade moral. Apresentar uma desculpa adequada bloqueia a inferência entre ação errada (wrongdoing) e culpabilidade (blameworthy). Wallace afirma que "Excuses aim precisely to challenge the claim (or suspicion) that $S$ was morally responsible for $X$; they adduce conditions that make it unfair to hold $S$ morally responsible for $X^{\prime \prime}(1994, p$. 121). Condições em que os agentes realizam ações sob condições de coerção são exemplos de inibidores de responsabilidade. Por outro lado, a isenção de responsabilidade se aplica aos casos de exceção (insanidade, vícios e crianças servem como exemplos, embora controversos em alguns casos) em que é apresentada um tipo de justificação adequada para as condições em que a ação é realizada. Nesse caso, "If $S$ offers a justification for doing $X$ then $S$ does not mean to deny responsibility for the act; rather, $S$ accepts responsibility for doing $X$, and tries to show why $X$ was a morally permissible (or even obligatory) thing to do" (Wallace, 1994, p. 120). Wallace, fazendo referência a J. L. Austin, chama isso de inibidores de culpabilidade (blameworthiness inhibitors).

24 Sobre esse problema, confira Brown, "Moral theory and the ought-can principle" (1977); Collingridge "Ought-implies-can and Hume's rule" (1977); Fischer, "Ought-implies-can, causal determinism and moral responsibility" 
(2003); Haines, "Ought and can" (1972); Robinson, "Ought and ought not" (1971); Sapontzis, "Ought does imply can" (1991); Schnall, "The principle of alternate possibilities and ought implies can" (2001); Sinnott-Armstrong, "Ought conversationally implies can" (1984); Stocker, "Ought and can" (1971).

25 Frankena distingue, ainda, entre juízos morais sobre obrigação e juízos sobre valor, afirmando que ambos são juízos normativos. Entretanto, enquanto o primeiro tipo de juízo se refere à noção de dever, juízos sobre valor não estão diretamente relacionados à norma ou ação, mas aos motivos, intenções ou traços de caráter do agente. Confira Frankena, 1975, 22-25.

26 Tradução minha. No original: "Unlike the idea of a moral obligation period, bipolar obligations have not only obligors, agents who are subject to the obligation, but also obligees, those to whom the obligation is owed. They thus entail a correlative claim right that the obligee has to claim of the obligor the conduct that the obligor is obligated to the obligee to perform (...) Both concepts are shown to be second personal, but in different ways. Someone is morally obligated to do something period just in case her doing it is something that anyone (including she) justifiably demands of her as a representative person. And someone is obligated to another to do something just in case the obligee has the individual discretionary authority to make demands of the obligor as the obligee and to hold the obligor personally accountable."

27 Tradução minha. No original: "(...) promisee has a distinctive normative standing or authority in relation to the promiser that third parties do not have."

28 Karen Jones nomeia um de seus artigos com a expressão "But I Was Counting On You!" exatamente para explorar a força normativa de normas em relação a obrigação de ser confiável. Ver Jones, 2017.

${ }^{29}$ Aqui, Darwall faz um pequeno arranjo para adequar à sua teoria. Cf. 2013, p. 27-31. A disposição original em M. Thompson (2004) é a seguinte:

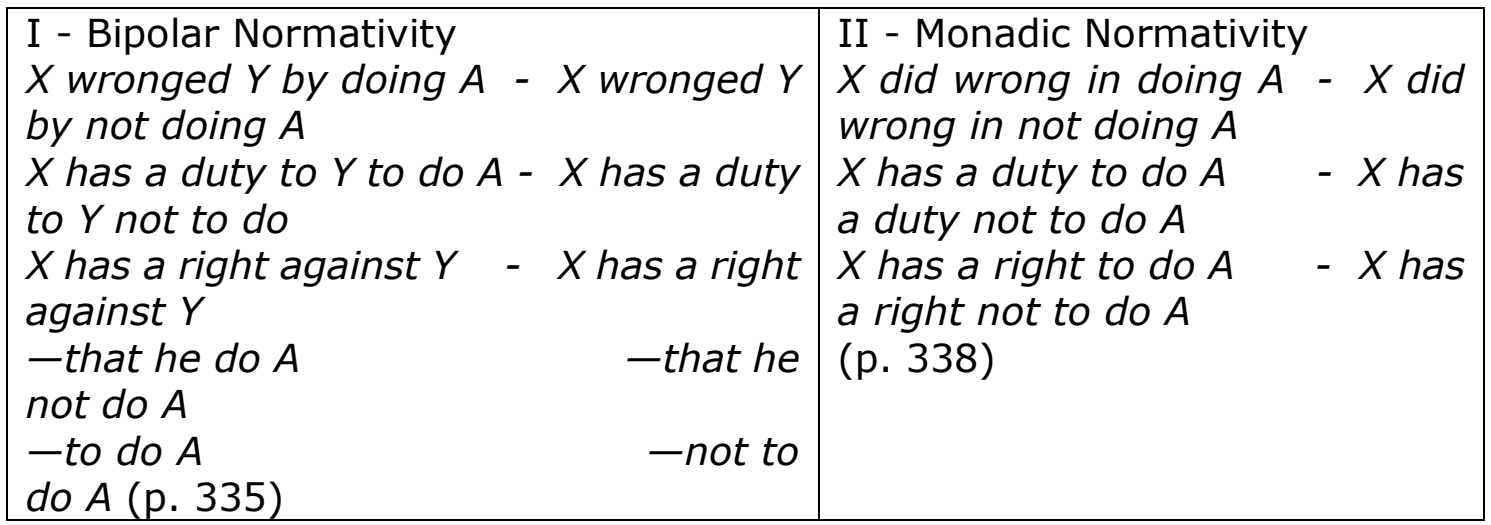

Thompson distingue normatividade bipolar e normatividade monádica com propósitos diferentes dos de Darwall. Enquanto o último considera essa distinção fundamental para entender os tipos de obrigações no domínio moral, especialmente quando considerada sua visão do relational duty que se 
manifesta em segunda pessoa, Thompson amplia a discussão e sua aplicação para outros domínios práticos, tal como a esfera legal. Confira Thompson, 2004 , p. 340-42.

${ }^{30}$ Como ele mesmo afirma, "(...) to hold someone an expectation, I maintain, is to be susceptible to the reactive attitudes in one's relations with the person" (p. 19).

31 Tradução minha. No original, destaques meus: "(...) bipolar obligations presuppose the individual authority of the obligee, moral obligations period presuppose a representative authority that any person has as a representative person or member of the moral community to hold themselves and others accountable for compliance through impersonal reactive attitudes."

32 Strawson explora este exemplo para indicar em quais condições eu teria o sentimento de ressentimento ou, se for o caso, gratidão (gratitude): "If someone treads on my hand accidentally, while trying to help me, the pain may be no less acute than if he treads on it in contemptuous disregard of my existence or with a malevolent wish to injure me. But I shall generally feel in the second case a kind and degree of resentment that I shall not feel in the first. If someone's actions help me to some benefit I desire, than I am benefited in any case; but if he intended them so to benefit me because of his general goodwill towards me, I shall reasonably feel a gratitude which I should not feel at all if the benefit was an incidental consequence, unintended or even regretted by him, of some plan of action with a different aim" (STRAWSON, 2013, p. 342).

33 Darwall dirá que ele possui razões em segunda-pessoa para realizar tal demanda: Razões em segunda-pessoa são razões "(...) cuja validade depende de relações pressupostas de autoridade e prestação de contas entre pessoas e, portanto, sobre a possibilidade desta razão ser endereçada de pessoa para pessoa. Razões endereçadas ou pressupostas em pedidos, solicitações, reivindicaçõos, censuras, reclamações, demandas, promessas, contratos, consentimentos, comandos, e assim por diante, são todas razões em segunda pessoa (...) Como razões em segunda- pessoa sempre derivam das relações entre os agentes uns com os outros, tais razões são, sem exceções, fundamentalmente razões relativas ao agente" (2006, p. 8, tradução minha). A distinção clássica entre razões neutras e razões relativas ao agente é encontrada em The View from Nowhere (1986) de Thomas Nagel. Comentários sobre a ideia de razão em segunda-pessoal pode ser encontrado em Barbosa, 2018a, especialmente na parte II - Conceitos em SegundaPessoa, e em Barbosa, 2018b.

34 Strawson (2013) afirma que, em alguns casos, podemos oferecer o perdão (forgiveness). Do modo como compreendo, uma ação feita com uma desculpa adequada e uma ação para a qual se oferece o perdão estão em categorias distintas. A ação feita acompanhada de uma desculpa adequada não é sequer passível de ser avaliada, ou seja, não há avaliação moral sobre esta. Por sua 
vez, a atitude reativa do perdão parece pressupor que a ação é errada, mas há uma concessão de minha parte do tipo não demandar e imputar culpa.

35 Darwall define que atitudes objetivas como desprezo, aversão e irritação estão em oposição às chamadas atitudes reativas, estas sendo reconhecidas como atitudes em segunda pessoa, dado que "they require involvement in an interpersonal dimension" (2013, p. 33). Strawson, por sua vez, alega: "If your attitude towards someone is wholly objective, then though you may fight him, you cannot quarrel with him, and though you may talk to him, even negotiate with him, you cannot reason with him. You can at most pretend to quarrel, or to reason, with him" (1968, p. 52). Portanto, uma atitude reativa pessoal como o ressentimento é sentida da perspectiva de uma das partes envolvidas da relação, enquanto atitudes reativas impessoais são sentidas por uma perspectiva de terceira pessoa, isso é, por aqueles não diretamente envolvidos. O ponto em comum é que ambas as atitudes reativas pessoais e impessoais são essencialmente interpessoais para Strawson ou em segunda pessoa de acordo com Darwall.

${ }^{36}$ No original: "(..) morally obligatory is what morality demands."

37 Nas palavras de Darwall: "My claim is that when we blame someone, whether someone else or ourselves, we implicitly address a demand, not at our own individual discretion, but as a representative person, on behalf of the moral community, as it were. Impersonal reactive attitudes like moral blame thus presuppose a representative authority that is complementary to the individual authority that is presupposed by bipolar obligations" (Darwall, 2013, p. 37).

38 Tradução minha. No original: "If $X$ has an obligation to $Y$ to do $A$, and $Y$ therefore a claim right against $X$ that $X$ do $A$, then $X$ 's failure to do $A$ would not only wrong $Y$, it would be wrong period, other things equal, at least".

39 Wallace explora a idea de autonomia que subjaz à noção de responsabilidade moral da seguinte forma: "To view people as responsible in this sense is to see them as autonomous agents who are reflective about their lives, who have a set of values or commitments sufficiently structured to constitute what we might call a "conception of the good" and who aim to advance that conception in their action" (1996, p. 52).

40 Tradução minha. No original: "obligation and wrong are normative not for action, but for Strawsonian reactive attitudes".

${ }^{41}$ Confira Erin I. Kelly, 2013, p. 246-7. 


\section{Referências bibliográficas}

ADAMS, Robert Merrihew. Involuntary Sins. The Philosophical Review, Vol. 94, No. 1, p. 3-31, janeiro, 1985.

ANSCOMBE, Gertrude E. M. Modern Moral Philosophy. In: CRISP, R.; SLOTE, M. (Eds.). Virtue Ethics. Oxford: Oxford University Press, 1998. p. 26-44.

. Reasons, Relations, and Commands. Ethics, Vol. 118, p. 24$36,2007$.

ANTON, Audrey L. Moral Responsibility and Desert of Praise and Blame. Lanham, Maryland: Lexington Books, 2015.

AUDI, Robert. Reasons for action (Parte II, 24). In: SKORUPSKI, J. (Ed.) The Routledge Companion to Ethics. New York: Routledge, 2010.

BAKER, Derek. The Varieties of Normativity. In: MCPHERSON, T.; PLUNKETT, D. (Eds.) The Routledge Handbook of Metaethics. New York: Routledge, 2017, p. 567-581.

BARBOSA, Evandro. Obrigações deontológicas no contratualismo moral de Thomas Scanlon. In: BRESOLIN, K.; BARBOSA, E. (Eds.) Temas de Filosofia Política. Caxias do Sul, RS: Educs, 2017. p. 08-30.

- O ponto de vista da segunda-pessoa, Parte I: uma fundamentação para o contratualismo? In: BARBOSA, E.; HOBUSS, J. (Orgs). Agência, Deliberação e Motivação. Pelotas: NepFil Online, 2018a, p. 89-112.

. O ponto de vista da segunda-pessoa, Parte II: obrigação moral

e o problema da responsabilidade. In: BARBOSA, E; HOBUSS, J. (Orgs.). Agência, Deliberação e Motivação - Volume II. Porto Alegre: Editora Fi, 2018b, p. 76-98.

BROOME, John. Normative Requirements, Ratio 12, 1999, p. 398-419.

BROWN, James. Moral theory and the ought-can principle, Mind 86, 1977 , p. 206-223. 
COATES, D. Justin. \& TOGNAZZINI, Neal. A. (Eds.). Blame: Its Nature and Norms. Oxford: Oxford University Press, 2013.

COLLINGRIDGE, D.G. Ought-implies-can and Hume's rule, Philosophy 52,1977 , p. 348-351.

COPP, David. Morality in a Natural World: Selected Essays in Metaethics. Cambridge: Cambridge University Press, 2007.

DARWALL, Stephen. The Second-Person Standpoint: Morality, Respect, and Accountability. Cambridge: Harvard Press, 2006.

. Morality, Authority, and Law (I). Oxford: Oxford Press, 2013.

. Honor, History, and Relationship: Essays In Second-Personal

Ethics II. Oxford: Oxford Press, 2013a.

FISCHER, John Martin. Ought-implies-can, causal determinism and moral responsibility, Analysis 63, 2003, p.244-250.

GERT, Bernard. Morality: Its Nature and Justification. Oxford: Oxford University Press, 2005.

GERT, Bernard. \& GERT, Joshua. The Definition of Morality. In: ZALTA, E. N. (Ed.). The Stanford Encyclopedia of Philosophy. Spring 2016 ed. [s.l: s.n.].

HARMAN, Gilbert. The Nature of Morality. Princeton: Princeton University Press, 1977.

JONES, Karen. But I Was Counting On You! In: FAULKNER, Paul; SIMPSON, Thomas. The Philosophy of Trust. 2017, p. 90-108.

KELIN, Erin I. What Is an Excuse? In: COATES, D. J.; TOGNAZZINI, N. A. (Eds.). Blame: Its Nature and Norms. Oxford: Oxford University Press, 2013, p. 244-262. 
KORSGAARD, Christine. The Sources of Normativity, Onora O'Neill (ed.), Cambridge: Cambridge University Press, 1996. doi: $10.1017 /$ СBO9780511554476

. The Normativity of Instrumental Reason. In: Cullity \& Gaut, p. 215-254, 1997. Reimpresso em Korsgaard, 2008. p. 27-68. doi:10.1093/acprof:oso/9780199552733.003.0002

MACNAMARA, Coleen. Taking Demands Out of Blame. In: COATES, D. J.; TOGNAZZINI, N. A. (Eds.). Blame: Its Nature and Norms. Oxford: Oxford University Press, 2013, p. 141-161.

MOODY-ADAMS, Michele M. Culture, Responsibility, and Affected Ignorance In: Ethics, Vol. 104, No. 2 (Jan., 1994), pp. 291-309.

NAGEL, T. The View from Nowhere. New York: Oxford University Press, 1986.

2004.

. Visão a partir de lugar nenhum. São Paulo: Martins Fontes,

NELKIN, Dana Kay. Making Sense of Moral Responsibility. Oxford: Oxford University Press, 2011.

PEREBOOM, Derk. Free Will Skepticism, Blame, and Obligation. in COATES, D. J.; TOGNAZZINI, N. A. (Eds.) Blame: Its Nature and Norms. Oxford: Oxford University Press, 2013, p. 189-206.

ROBINSON, Richard. Ought and ought not. Philosophy 46, 1971, p. 193-202.

ROSEN, Gideon. Skepticism about Moral Responsibility. Philosophical Perspectives, 18 (1), 2004, p. 295-313.

SAPONTZIS, Steve F. Ought does imply can. The Southern Journal of Philosophy 29, 1991, p. 383-393.

SCHNALL, Ira M. The principle of alternate possibilities and "ought" implies "can". Analysis 61, 2001, p. 335-340. 
SINNOTT-ARMSTRONG, Walter. Ought conversationally implies can, The Philosophical Review 93, 1984, p. 249-261.

STOCKER, Michael. (1971): Ought and can. Australasian Journal of Philosophy 49, 1971, p. 303-316.

SCANLON, Thomas M. What We Owe to Each Other. Cambridge: Harvard University Press, 1998.

. Moral Dimensions: Permissibility, Meaning, Blame. Cambridge:

Cambridge University Press, 2008.

SHER, George. In Praise of Blame. Oxford: Oxford University Press, 2006.

SIDGWICK, Henry. Outlines of the History of Ethics for English Readers. Boston, MA: Beacon Press, 1964.

STRAWSON, Peter Frederick Freedom and Resentment. Proceedings of the British Academy, 48, 1962, p. 1-25.

. Freedom and Resentment. In: Ethical Theory: An Anthology. 2nd. Edition. Ed. Russ Shafer-Landau. Oxford: Wiley-Blackwell, 2013.

. Liberdade e ressentimento. In: CONTE, J.; GELAIN, I. L. (Eds.) Ensaios sobre a filosofia de Strawson. Florianópolis: Editora da UFSC, 2015. p. 245-269.

THOMPSON, Michael. What Is It to Wrong Someone? A Puzzle about Justice. In: WALLACE, R. J. (Ed.) Reason and Value: Themes from the Moral Philosophy of Joseph Raz. New York: Oxford University Press, 2004. p. 333-84.

WALLACE, Jay, R. Responsibility and the Moral Sentiments. Cambridge, MA: Harvard University Press, 1994.

- Dispassionate Opprobrium: On Blame and the Reactive Sentiments. In: Reason and Recognition: Essays on the Philosophy of T. M. Scanlon. Wallace, R. J.; Kumar, R.; Freeman, S. (Eds.) New York: Oxford University Press, 2011. 
WATSON, Gary "Free Agency", The Journal of Philosophy, 72(8), 1975, 205-220. doi:10.2307/2024703

- Responsibility and the Limits of Evil: Variations on a Strawsonian Theme. Schoeman, 1987 [2004], p. 256-286. Reprinted in Watson 2004: 219-259. doi:10.1017/СBO9780511625411.011

. Two Faces of Responsibility. Philosophical Topics, 24(2), 1996 [2004], p. 227-248. Reimpresso em Watson 2004: 260-88. doi: $10.5840 /$ philtopics 199624222

Agency and Answerability: Selected Essays. New York: Oxford University Press, 2004. doi:10.1093/acprof:oso/9780199272273.001.0001

WOLF, Susan. Freedom within Reason. New York: Oxford University Press, 1990.

. Asymmetrical Freedom. The Journal of Philosophy, 77(3), 1980 , p. $151-166$. doi: $10.2307 / 2025667$

. Sanity and the Metaphysics of Responsibility. Schoeman, 1987, p. 46-62. doi:10.1017/CBO9780511625411.003

Blame, Italian Style. Reasons and Recognition: Essays on the Philosophy of T. M. Scanlon, Ed. R. Jay Wallace, Rahul Kumar e Samuel Freeman. New York: Oxford Univerity Press, 2011. 